\title{
Assessment of Frozen Semen Quality through Foldscope Microscopy- A Novel Application of Frugal Science to Reduce the Infertility Rate
}

\author{
P. Mooventhan, Mamta Choudhary
}

10.18805/IJAR.B-4699

\begin{abstract}
Background: Quality determination of frozen semen before using for Artificial Insemination (Al) in cattle is of paramount importance. The success of cattle Al programs is largely depends on the use of good quality semen and thus assessment of semen quality parameters before Al will improve the conception rate and reduces the loss associated with repeated breeding. Among the various semen quality indicators, sperm motility is one of the important parameter and it should be evaluated immediately after semen collection (before freezing) and 24 hrs after freezing as per minimum standard protocol in frozen semen production. Though the motility is a major determinant of spermatozoa ability to reach the site of fertilization and it is affected by cryopreservation and subsequent poor cold storage facilities, motility is not frequently evaluated under field conditions. In the current scenario, many of our government Al sub-stations in remote villages are not equipped with microscope facility for semen quality evaluation before Al.

Methods: In this study, we used foldscope, an origami-based paper microscope which give optical quality similar to conventional microscopes (magnification of $140 \mathrm{X}$ and 2-micron resolution), to evaluate the frozen semen motility at field level. In this study, the motility of spermatozoa was observed under foldscope and concluded that foldscope is very useful to asses the motility befor Al and improve the fertility in dairy animals.

Result: We revealed that, utility of foldscope to assess the motility of spermatozoa was evaluated under field conditions and observed that $46 \%$ of sperms were motile. Further, evalaution of sperm motility before $\mathrm{Al}$ is not very common practice due to lack of microscope in many Al centres. Therefore, foldscope will be very useful at field conditions to avoid Al using poor quality semen and subsequent loss associated with repeat breeding problems.
\end{abstract}

Key words: Foldscope, Semen quality, Spermatozoa motility.

\section{INTRODUCTION}

Indian dairy sector is the appropriate example for technology driven enhancement of the milk productivity where, 24 and $153 \%$ increase in cattle and buffalo population between 1951 and 2019 , led to the $1004 \%$ increase of milk production during the corresponding period.

Among the various technologies, Artificial Insemination (AI) coupled with improved nutrition and management has played an important role in genetic improvement and production enhancement in cattle and buffaloes. However, the potential of Al has not been harnessed to its fullest extent in India, despite of having one of the largest networks for livestock breeding, as overall Al coverage in dairy animals in India is only $30 \%$ that too with the lesser conception rate of $35 \%$ (Thirunavukkarasu and Kathiravan, 2009; Shaji et al. 2021). Low conception rate with $\mathrm{Al}$ is often cited as one of the major reasons for poor adoption of the technology by farmers (Rathod et al. 2017). One of the major reasons for low conception rate is the quality of the semen used for Al which is mainly due to inadequate cold chain maintenance during transport and storage at field conditions, which results in insemination of cows with poor quality semen (Lieberman et al. 2017).

Sperm motility is one of the important pre-requisite for high conception rates at field conditions, but it is not regularly assessed before Al due to inadequacy of microscope
ICAR-National Institute of Biotic Stress Management, Raipur493 225, Chhattisgarh, India.

Corresponding Author: P. Mooventhan, ICAR-National Institute of Biotic Stress Management, Raipur-493 225, Chhattisgarh, India. Email: p.mooventhan@icar.gov.in

How to cite this article: Mooventhan, P. and Choudhary, M. (2022). Assessment of Frozen Semen Quality through Foldscope Microscopy-A Novel Application of Frugal Science to Reduce the Infertility Rate. Indian Journal of Animal Research. DOI: 10.18805/ IJAR.B-4699.

Submitted: 01-07-2021 Accepted: 03-01-2022 Online: 22-02-2022 particularly in Al centers at remote villages. Motility is paramount for the sperm to pass through the barriers in female reproductive tract and to reach the site of fertilization within appropriate time. On the other hand, majority of the inseminated sperm were lost from reproductive tract by retrogressive movement within 12 hrs of insemination and only a small proportion of sperm were reaching site of fertilization. Therefore, it is important to estimate the sperm motility before Al to avoid straw containing more number of non-motile sperms and also to identify the straws with sufficient motile sperm to reach the site of fertilization.

Foldscope is ultra-affordable, Origami-Based Paper Microscope and weighs about 8 grams (Plate 1). It is hands- 
on, portable, durable microscope and to give optical quality similar to conventional research microscopes (magnification of $140 \mathrm{X}$ and 2-micron resolution). The magnification power is enough to enable the spotting of organisms such as Leishmania donovani and Escherichia coli, as well as malarial parasites. Foldscope can be used to observe biological samples like bacteria, copepods, tardigrades, tetrahymena, diatoms, rotifers, nematodes, spider eggs, ants, vorticella, mites, daphnia, etc., Foldscope can also allow the observation of non-biological samples, such as particulates detrimental to air quality, or the microscopic crystalline differences between real and fake medications. The Foldscope comes in a kit with multiple lenses that provide magnification from $140 \mathrm{X}$ to $2,000 \mathrm{X}$. A Foldscope can be printed on a standard A4 sheet of paper and assembled in seven minutes. It is part of the "frugal science" movement which aims to make cheap and easy tools available for scientific use in the developing world (Cybulski et al. 2014). Foldscope was invented by Manu Prakash and Jim Cybulski at the Department of Bioengineering, Stanford University, California, USA in 2014 and designed to cost less than US\$1 to build. Foldscope can be coupled with smart phones to capture images and videos through in build magnetic couplers. The LED light attachment is very unique and useful to provide phase contrast like view for visualizing any sample mounted on a microscope slide.

\section{MATERIALS AND METHODS}

Frozen semen quality analayis under Foldscope

The study was conducted at State Veterinary Referral Hospital, Raipur, Chhattisgarh (India) (Plate 3). About 10 frozen semen straws of from Gir bulls were obtained and evaluated in this study. The frozen semen straw was taken out from a $-196^{\circ} \mathrm{C}$ container, wiped it immediately with a clean cotton and placed it in a $37^{\circ} \mathrm{C}$ water bath for $30 \mathrm{~s}$. After wiping the straws, the laboratry seal was cut and a drop of semen was placed in a prewarmed $\left(37^{\circ} \mathrm{C}\right)$ clean, grease free glass slide, overwhich a cover slip was applied. The samples were observed under the foldscope for sperm motility visualization. The sperm motility was asessed in at least five fileds and expressed as percentage rounded to nearest $5 \%$ (Plate 2).

\section{RESULTS AND DISCUSSION}

In India about $30-40 \%$ of the dairy cattle and buffalo population suffers due to infertility problems which cost about INR 50000 crores annualy (NAAS, 2013). A failed insemination would cost about Rs 1051 per cow under Indian dairy faring conditions (Thirunavukkarasu and Kathiravan, 2006). In this study, utility of foldscope to assess the motility of spermatozoa was evaluated under field conditions and

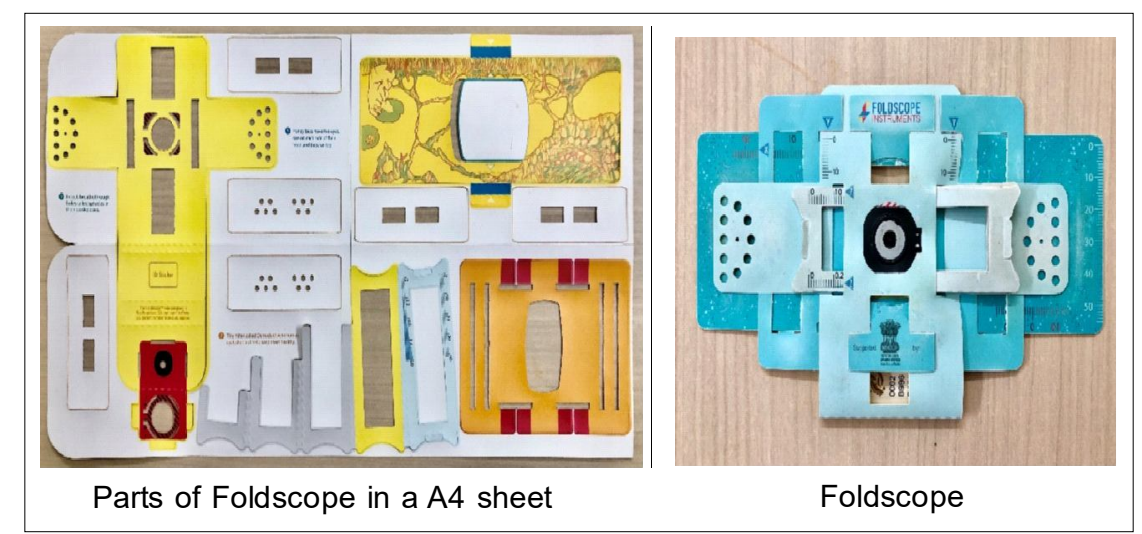

Plate 1: Parts of foldscope.

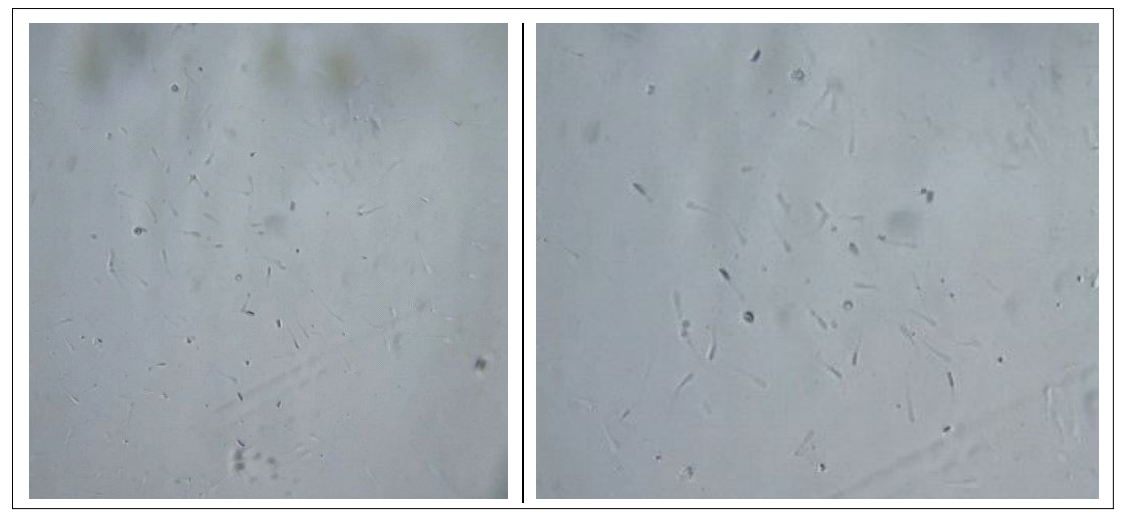

Plate 2: Images of individual motility of spermatozoa observed through foldscope. 


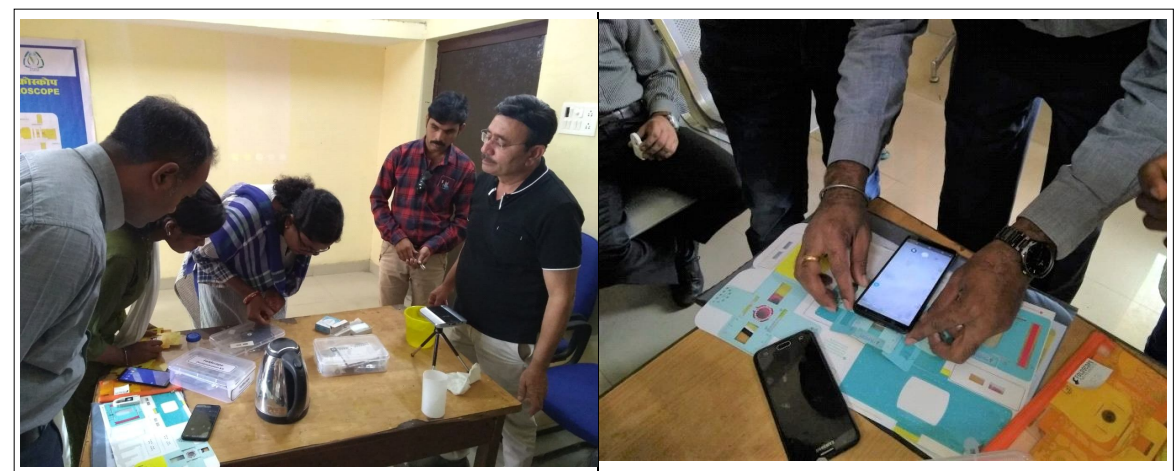

Plate 3: Training to Veterinary Assistant Surgeon (VAS) for field level evaluation of semen quality through foldscope microscopy at State Veterinary Referral Hospital, Raipur, Chhattisgarh.

observed that $46 \%$ of sperms were motile. Generaly, spermatozoa motility is evaluated after freezing in semen stations and distributed for Al to field conditions. After that, evalaution of sperm motility before $\mathrm{Al}$ is not very common practice due to lack of microscope in many Al centres. Therefore, foldscope will be very useful at field conditions to avoid Al using poor quality semen and subsequent loss associated with repeat breeding problems. Improvements of foldscope to overcome the present constraints are also required. For instances, the main issue with the foldscope is while holding the microscope up to a light source resulted in the liquid sample dripping on the observers face. This is not only relevant to difficulty in handling but also make possible to contact with biological samples and exposure to infectious organisms to skin, eyes or mouth, if any. Therefore, suitable modification to keep it flat and hold it near light source may be useful to avoid the contact the examiners with biological samples. In addition, development of methods to take the images or videos of sperm motility with tablet or mobiles and subsequent analysis by using suitable software like ImageJ will be very useful at field conditions.

\section{CONCLUSION}

Utility of foldscope to evaluate the individual motility of spermatozoa was studied and found useful techniques under field conditions. If the Image $J$ or other image processing software developed for mobile version, the complete process of semen quality evaluation can be done in the field with minimal time and cost. This field application of foldscope will certainly increase the cenception rate of cattle per $\mathrm{Al}$ and save the money and time as well.

\section{ACKNOWLEDGEMENT}

Authors are grateful to Department of Biotechnology for providing the financial grant (Admin order No: BT/IN/IndoUS/Foldscope/39/2015 dated 20.03.2018) under the research project 'Surveillance and minimising the risk of zoonotic diseases among tribal farmers through Foldscope microscopy'and facilities to carry out the research work. Authors are also thankful to Director, ICAR - National Institute of Biotic Stress Management, Raipur, Chhattisgarh for necessary help. The PME reference number for this paper is ICAR-NIBSM/RP-24/2020-1/40.

\section{Conflict of interest: None.}

\section{REFERENCES}

Cybulski, J.S., Clements, J. and Prakash, M. (2014). Foldscope: Origami based paper microscope. PLoS ONE. 9: e98781.

Lieberman, D. McClure, E., Harston S. and Madan, D. (2017). Maintaining semen quality by improving cold chain equipment used in cattle artificial insemination. Sci. Rep. 6: 28108.

Rathod, P., Chander, M. and Sharma, C.G. (2017) Adoption status of artificial insemination in Indian dairy sector: application of multinomial logit model, J Appl. Anim. Res. 45(1): 442-446.

Shaji, A., Elango, K. and Kumaresan, A. (2021). Prolonged oestrus as a cause of infertility in dairy cattle-A review. Indian J. Dairy Sci. 74(5): 379-386.

Thirunavukkarasu, M. and Kathiravan, G. (2006). Factors influencing economic losses due to conception failures in artificially inseminated bovines. Tamil Nadu J. Vet. Anim. Sci. 2(6): 208-211.

Thirunavukkarasu, M. and Kathiravan, G. (2009). Factors affecting conception rates in artificially inseminated bovines. Indian J. Anim. Sci. 79(9): 871-875. 